\title{
The field investigation on thermal comfort of tent in early autumn of Tianjin
}

\author{
Hao Yang ${ }^{1, a}$,Yingni Jiang ${ }^{2, b}$,Jingbo Liu ${ }^{3, c}$ Zhengguo Gong ${ }^{4, d}$ \\ Architecture Engineering Department, Logistics University of PAP, Tian'jin, china \\ ${ }^{a}$ E-mail address:849253712@qq.com, ${ }^{b}$ E-mail address: jyingni@sina.com \\ ${ }^{c}$ E-mail address:568818102@qq.com, ${ }^{d}$ E-mail address:782101251@qq.com
}

\begin{abstract}
In a university campus in Tianjin, four tents were set up to investigate the thermal environment and thermal comfort. Both the field investigation and questionnaires were adopted in this experiment. Two hundred people were investigated, and two hundred questionnaires were gotten. The results show that the thermal comfort zone of officers and soldiers is $24^{\circ} \mathrm{C}$ to $28^{\circ} \mathrm{C}$ in early fall, it is a wide range. There is a big error between the PMV index and the actual survey results, PMV calculation index is not accurate in tents environment. The results will have a significant effect on improving the thermal comfort of tents..
\end{abstract}

\section{Introduction}

In this paper, through test the thermal comfort conditions of tent, analysis the influence of factors on the thermal comfort degree, such as temperature, relative humidity, wind speed, etc. the questionnaire survey is carried out in the tent, and the actual environment parameters were measured. Combining with the parameter and questionnaire to find the best appropriate temperature range inside the tent, and compare the PMV with the thermal sensation MTS [1], which find the difference between the two factors. The research has reference meaning in improving the thermal environment in tents.

\section{Research CONTENTS AND METHODS}

\subsection{Survey site}

The survey site is located in a certain college of Tianjin, at the address of Tianjin dong li nearing the sea. The air flow rate is large outside. There are four tents which are far away and have no effect on each other.

\subsection{The investigation of the time and weather conditions}

The investigation was established from September 12, 2015 to September 22, 2015. The temperature and relative humidity recorder were used to measure the data throughout the day. It was carried out every half our. On September 15, for example, the temperature and relative humidity had a wide range. The temperature ranged from 16 to 36 degrees. The distribution of the temperature had twenty degrees. And the relative humidity ranged from $23 \%$ to $70 \%$, the average of the relative humidity was $45 \%$. The change of temperature and humidity are shown in figure1.

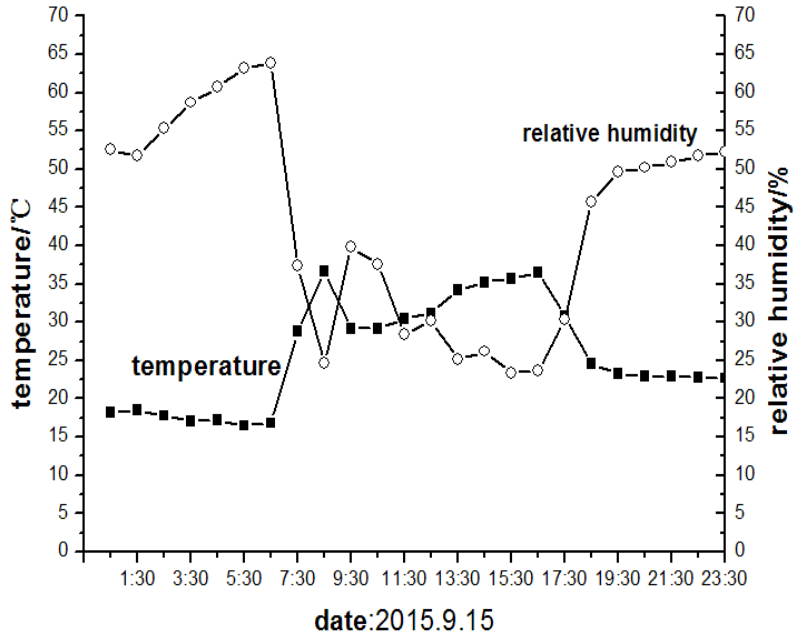

Figure 1: the change of temperature and humidity in whole day during the investigation

\section{Research Analysis and methods}

\subsection{The environment parameters in tent and the results of the questionnaires}

The thermal environment parameters in tent and the results of the questionnaires are shown in table 1, including the temperature, the relative humidity, the black ball temperature, and the air velocity, PMV (The predicted average index of thermal sensation vote), TSV (thermal sensation vote) and DPV (the air velocity sensation vote)[2]. 
Table 1: the questionnaires about the thermal environment parameters in tent

\begin{tabular}{|c|c|c|c|c|}
\hline & $\begin{array}{c}\text { the } \\
\text { averag } \\
\text { e value }\end{array}$ & $\begin{array}{c}\text { standard } \\
\text { deviatio } \\
\mathrm{n}\end{array}$ & $\begin{array}{l}\text { maximu } \\
\text { m value }\end{array}$ & $\begin{array}{l}\text { minimu } \\
\text { m value }\end{array}$ \\
\hline $\begin{array}{c}\text { air } \\
\text { temperatur } \\
\mathrm{e}\end{array}$ & 27.40 & 2.74 & 36.40 & 22.60 \\
\hline $\begin{array}{l}\text { relative } \\
\text { humidity }\end{array}$ & 45.00 & 0.06 & 57.00 & 37.00 \\
\hline air velocity & 1.80 & 2.43 & 8.20 & 0.06 \\
\hline $\begin{array}{c}\text { mean } \\
\text { radiant } \\
\text { temperatur } \\
\mathrm{e}\end{array}$ & 29.97 & 3.14 & 37.50 & 25.40 \\
\hline $\begin{array}{c}\text { the black } \\
\text { ball } \\
\text { temperatur } \\
\text { e }\end{array}$ & 27.80 & 2.02 & 32.31 & 23.20 \\
\hline PMV & 1.60 & 0.57 & 2.80 & 0.80 \\
\hline TSV & 1.12 & 0.52 & 2.50 & -1.00 \\
\hline DPV & -1.00 & 1.20 & 2.00 & -3.00 \\
\hline
\end{tabular}

During the experiment, each test was regarded as a condition. A total of thirty questionnaires and parameter test were conducted. The average temperature of each test is shown in figure 2 and figure 3.

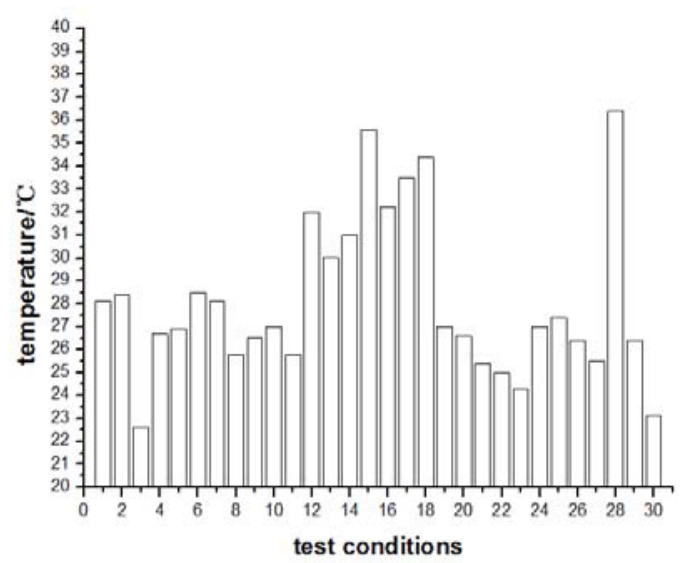

Figure 2: The distribution of average temperature on each test in tent

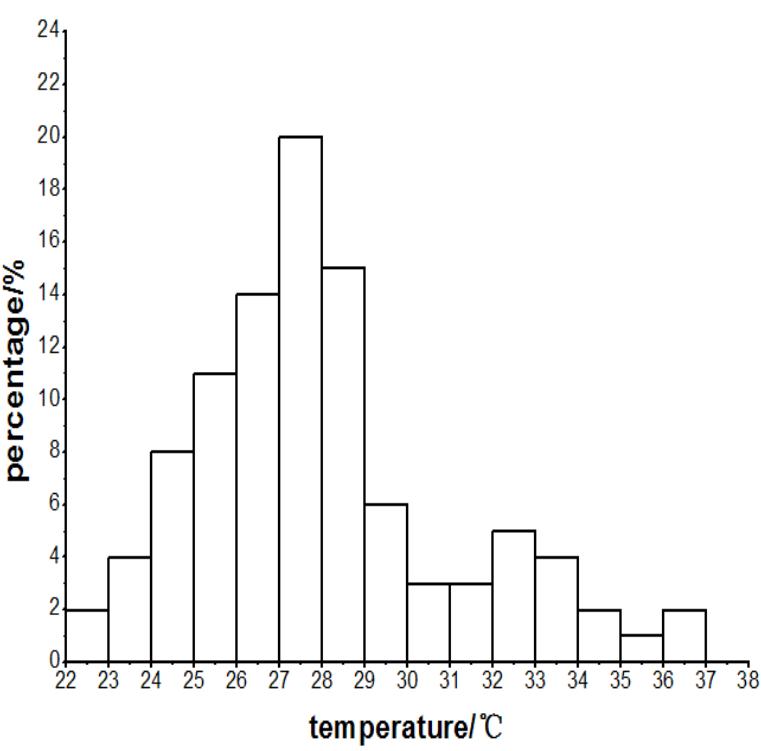

Figure 3: frequency distribution of the average temperature

There are thirty groups of test in total. The average temperature of each group was calculated. As you can see in figure 2 , figure 3 . There is a wide variety among the average temperature. Under the conditions of the experiment, the average temperature in tent is distributed from 22 to 37 degrees. The highest temperature can reach to 36.4 degree, and the lowest temperature is 22.6 degree. The temperature in the tent is high on the whole. Most of the temperature range from 24 to 29 degrees, it accounts for sixty-eight percent of the whole samples.

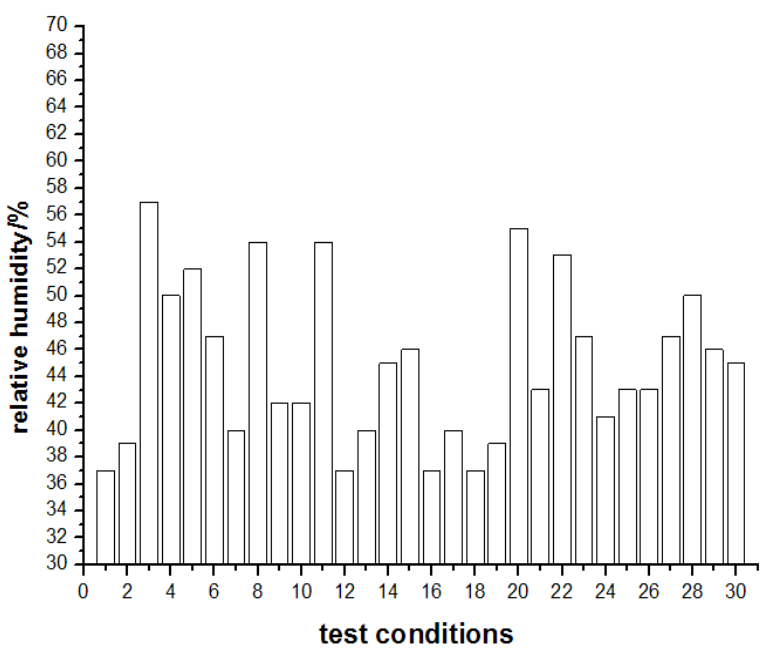

Figure 4: The distribution of the relative humidity on each test in tent 


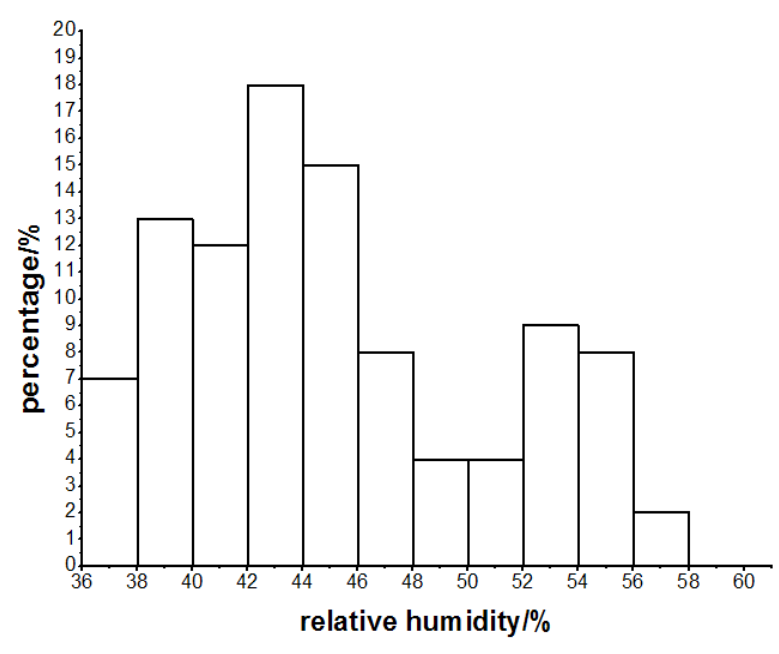

Figure 5: frequency distribution of the relative humidity

As you can see in figure 4, figure 5, under the conditions of the experiment, the relative humidity in tent is distributed from thirty-seven percent to fifty-seven percent. There is little variation on the relative humidity. The average humidity is forty-five percent, the relative humidity outside is also forty-five percent. Therefore the relative humidity is satisfied with normal result.

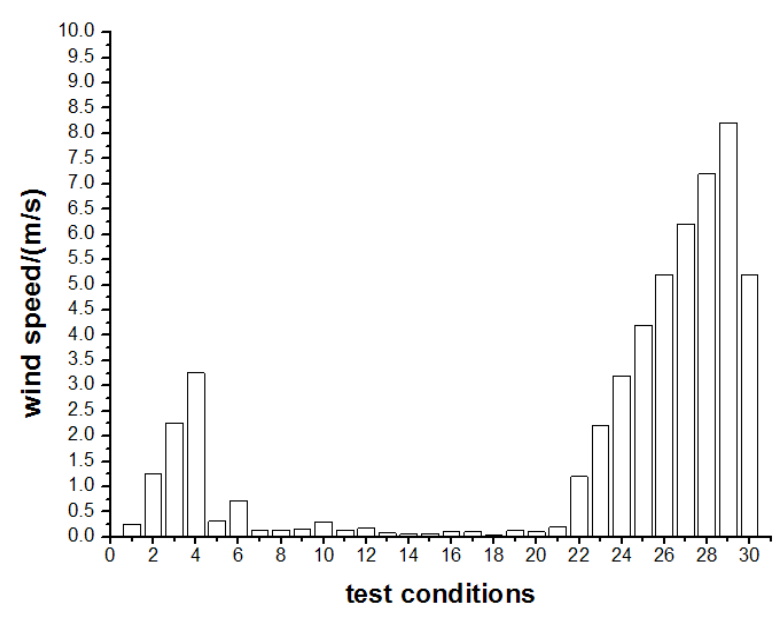

Figure 6: The distribution of the wind speed on each test in tent

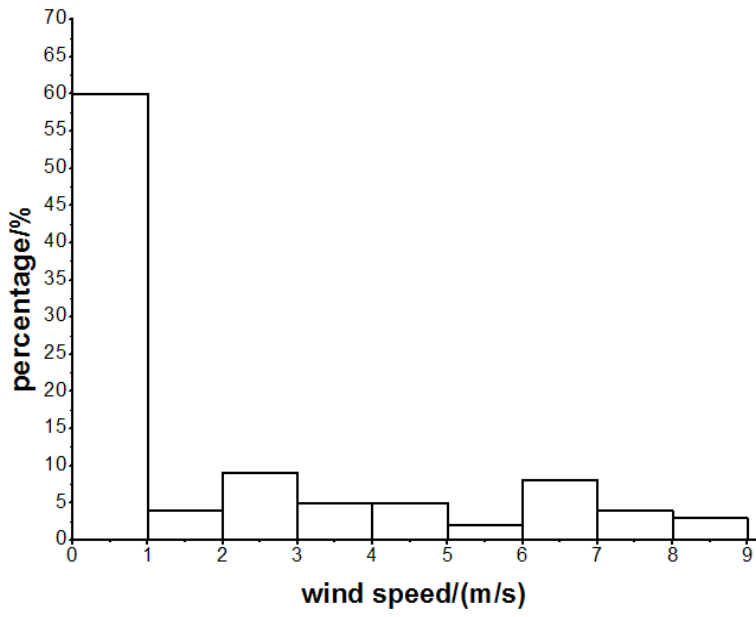

Figure 7: frequency distribution of the wind speed

As you can see in figure 6, figure 7 , there is large variation on the air velocity in tent, range from 0.06 meters per second to 8.20 meters per second. Frequency distribution of the wind speed is polarized. Sixty percent of the wind speed is less than 1 meter per second, it illustrates that the air velocity is small on the whole during the experiment. But the result also have 15 percent of wind speed is more than 6 meters per second, it illustrates that the wind speed has a large variation.

\subsection{The effect of temperature on the thermal comfort}

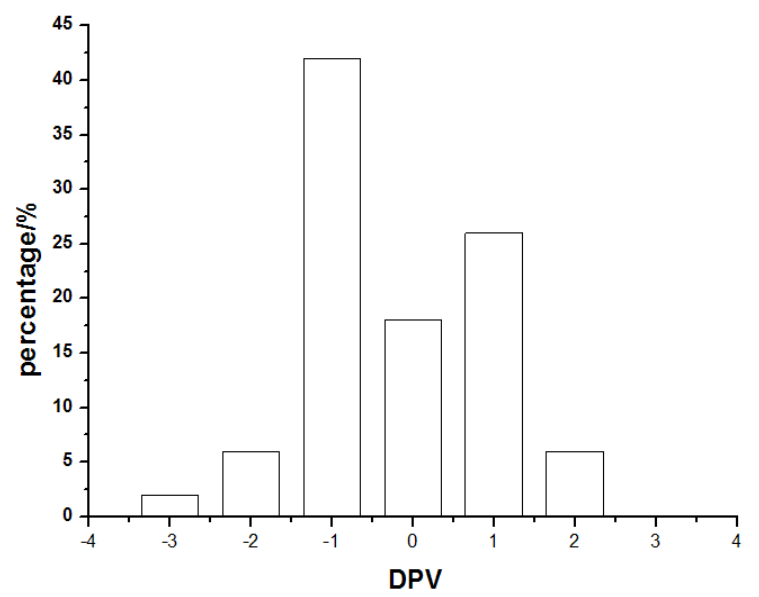

Figure 8: frequency distribution of the DPV

As you can see in figure 8, the reason why forty-two percent of the people feel a little stuffy in tent is that sixty percent of the wind speed is less than 1 meter per second when we have tested before. Meanwhile, according to the previous data, we can know that the wind speed is changing rapidly during the experiment, and the wind speed is polarized. So it gives an explanation on the consequence that twenty-six percent of people feel that there exist breeze, and eight percent of people feel a draft. 


\section{Discussing}

\subsection{The comparison between the measured results and PMV}

The PMV index represents the thermal sensation of most people, and it can predict the thermal sensation of people in the changing environment. The index is mainly used to provide a reference value of the thermal comfort. The PMV value can be divided into seven phases. When the PMV value is +3 , it means that the thermal comfort is the hottest. And When the PMV value is $-3[3]$, it means the thermal comfort is the coldest. The value is 0 , which means the thermal comfort is moderate. According to the ISO7730, the calculation equation of PMV is shown as follows:

$\mathrm{PMV}=\left[0.303 \mathrm{e}^{-0.036 M}+0.028\right]\left\{\mathrm{M}-\mathrm{W}-3.05^{*} 10^{-3}[5733-6\right.$
$\left..99(\mathrm{M}-\mathrm{W})-\mathrm{P}^{\mathrm{a}}\right]-0.42[(\mathrm{M}-\mathrm{W})-58.15]-1.7 * 10^{-5} \mathrm{M}\left(5867-\mathrm{P} \mathrm{a}^{-}\right)-$
$0.0014 \mathrm{M}(34-\mathrm{t} a)-3.96 * 10^{-8} \mathrm{f}^{c l}\left[(\mathrm{t} c l+273)^{4}-\left(t_{r+273)}{ }^{4}\right]-\right.$
$\left.\mathrm{f}^{c l} l_{\mathrm{h}}{ }^{c}(\mathrm{t} c l-\mathrm{t} a)\right\}[4]$
According to compare the calculated mean thermal sensation index PMV with the measured mean thermal sensation index MTS, the consequence is shown in figure 9.

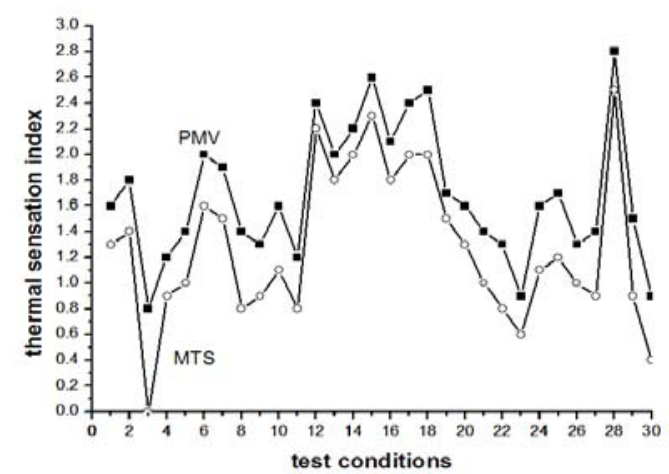

Figure 9: the value of PMV and MTS on each condition

According to figure 10, the PMV index in the ISO7730 exist a big error when it predicts the thermal environment in tent. The calculated result of the index underestimates the tolerance of the officers and soldiers. They have lived in tents for a long time, so they have some adaptability to the thermal environment of the tent. Therefore it is not accurate to use the PMV index to predict the officers and soldiers' comfort condition. The ordinary people feel a little hot in certain situation while the officers and soldiers feel it is comfortable. So a new evaluation model should be used to predict the thermal environment in tent.

\section{Conclusions}

(1) During the experiment, the range of parameters is ${ }_{\mathrm{t}} a=22.6^{\circ} \mathrm{C} \sim 36.4^{\circ} \mathrm{C}, \varphi=37 \% \sim 57 \%, \quad t_{r}=25.4^{\circ} \mathrm{C} \sim 37.5^{\circ} \mathrm{C}$, $\mathrm{v}=0.06 \mathrm{~m} / \mathrm{s} \sim 8.20 \mathrm{~m} / \mathrm{s}$, the temperature and wind speed have a large variation, but there is little variation on the relative humidity, the radiant temperature is high.

(2) The wind speed has a significant effect on the thermal comfort in tent, and there is sixty percent of the wind speed that is less than 1 meter per second. Therefore forty-two percent of the people feel a little stuffy in tent. The reason why twenty-six percent of people feel that there exist breeze, and eight percent of people feel a draft is that many people are tend to sit near the window and door when they are tested, and another reason is that the wind speed has a great change during the experiment.

(3)The PMV index in ISO7730 is mainly used to predict the air conditioning environment. It will have some errors when it is used in non-air-conditioned environment. The result is different from the measured one, because the PMV index doesn't consider the officers and soldiers' adaptation to the tent. The ordinary people feel a little hot in certain situation while the officers and soldiers feel it is comfortable. Therefore, the interval value of the comfortable temperature is large.

\section{References}

1. Yingxin ,Zhu. Building environment(third edition).Beijing: China architecture,2010.

2. Qian, $\mathrm{Wu}$. Study on the relationship between indoor air velocity and human comfort and physiological stress [D]. Chongqing university, 2005

3. Fangjiu,Li,Ning,Lv. Measurement and evaluation of thermal environment in winter in a college classroom in Guangzhou[J]. Fujianarchitecture,2012,08:104-106.

4. Huaqiu,Tao, Li,Li. Thermal environment test and thermal comfort prediction of Xiamen university classroom in winter[J].HVAC,2012,04:72-75. 